\title{
Non-targeted and targeted metabolomics profiling of tea plants (Camellia sinensis) in response to its intercropping with Chinese chestnut
}

\author{
Tian $\mathrm{Wu}^{1^{*}}$ (D), Rui Zou' ${ }^{1}$, Dian Pu', Zengquan $\operatorname{Lan}^{3}$ and Bingyu Zhao ${ }^{4}$
}

\begin{abstract}
Background: Intercropping is often used in the tea producing areas where land resources are not so abundant, and the produced green tea is tasted more delicious through a tea-Chinese chestnut intercropping system according to the experience of indigenous farmers. The length and weight of tea leaf increase under this intercropping system and their root systems are stratified vertically and coordinate symbiosis. However, the delicacy mechanism under the intercropping is not fully understood.

Results: Green tea from the Chinese chestnut-tea intercropping system established in the 1980s ranked highest compared with a pure tea plantation from the same region. Based on the non-targeted metabolomics, 100 differential metabolites were upregulated in the tea leaves from intercropping system relative to monoculture system. Twenty-one amino acids were upregulated and three downregulated in response to the intercropping based on the targeted metabolomics; half of the upregulated amino acids had positive effects on the tea taste. Levels of allantoic acid, sugars, sugar alcohols, and oleic acid were higher and less bitter flavonoids in the intercropping system than those in monoculture system. The upregulated metabolites could promote the quality of tea and its health-beneficial health effects. Flavone and flavonol biosynthesis and phenylalanine metabolism showed the greatest difference. Numerous pathways associated with amino acid metabolism altered, suggesting that the intercropping of Chinese chestnut-tea could greatly influence amino acid metabolism in tea plants.

Conclusions: These results enhance our understanding of the metabolic mechanisms by which tea quality is improved in the Chinese chestnut-tea intercropping system and demonstrate that there is great potential to improve tea quality at the metabolomic level by adopting such an intercropping system.
\end{abstract}

Keywords: Camellia sinensis, Chinese chestnut, Amino acid, LC-MS, Agroforestry, Metabolic pathway

\footnotetext{
* Correspondence: wutianpotato@swfu.edu.cn

'Key Laboratory for Forest Resources Conservation and Utilization in the Southwest Mountains of China, Ministry of Education, Southwest Landscape Architecture Engineering Research Center of State Forestry Administration, Southwest Forestry University, Kunming 650224, Yunnan, China

Full list of author information is available at the end of the article
}

(C) The Author(s). 2021 Open Access This article is licensed under a Creative Commons Attribution 4.0 International License, which permits use, sharing, adaptation, distribution and reproduction in any medium or format, as long as you give appropriate credit to the original author(s) and the source, provide a link to the Creative Commons licence, and indicate if changes were made. The images or other third party material in this article are included in the article's Creative Commons. licence, unless indicated otherwise in a credit line to the material. If material is not included in the article's Creative Commons licence and your intended use is not permitted by statutory regulation or exceeds the permitted use, you will need to obtain permission directly from the copyright holder. To view a copy of this licence, visit http://creativecommons.org/licenses/by/4.0/. The Creative Commons Public Domain Dedication waiver (http://creativecommons.org/publicdomain/zero/1.0/) applies to the data made available in this article, unless otherwise stated in a credit line to the data. 


\section{Background}

Tea [Camellia sinensis (L.) O. Kuntze] is a vital crop consumed worldwide, primarily in the form of a beverage processed by fresh leaves in different ways [1]. Tea originated as an understory plant of the tropical rainforest and therefore, it prefers warm, moist, shaded conditions with diffuse light and acidic soils [2]. Given these preferences, agroforestry intercropping systems offer a convenient strategy for tea cultivation and conservation. Agroforestry intercropping is an ancient and effective planting method in which one plant species is grown alongside another, thereby increasing yields and economic returns, reducing weeds and pests, improving light interception and utilization, and increasing iron nutrition, among other benefits [3-6]. Agroforestry intercropping has been commonly practiced in many parts of the world where arable land is scarce and hunger remains $[7,8]$.

The strategy of interplanting tea with other tree species has been developed in various forms and applied in different tea-producing regions. Some tall tree species are used as shade trees in tea plantations, including coconut (Cocos nucifera), orange (Citrus reticulata), waxberry (Myrica rubra), loquat (Eriobotrya japonica), and gingko (Ginkgo biloba) [9]. Because of the decreased use of pesticides in intercropping tea plantations, the resulting tea leaves are likely to have less chemical contamination problems [9]. Intercropping of rubber and tea to ameliorate land degradation has been practiced in mountain areas susceptible to soil erosion. For example, intercropped cultivation of rubber and tea plant was recommended to some provinces of China in the 1970s, which resulted in positive results on tea quality and soil and water conservation and tea quality [10].

Chinese chestnut (Castanea mollissima Blume) and tea plants are classic intercropping partners, and researchers have studied some different aspects of the Chinese chestnut-tea intercropping system. Chinese chestnut is one of the leading economically important species in the chestnut species [11]. As practiced in northern China, chestnut-tea intercropping reduces the intensity of illumination on tea plants, lowering air and soil temperatures around the plants, thereby increasing air humidity. This altered microclimate can improve tea quality and yield [12]. The intercropping system allows the root systems of Chinese chestnut and tea plants to be stratified vertically and coordinate the symbiosis, which increases the dry weight of tea plants' root system [13]. In addition, the improved soil structure in the intercropping system also results in increased plant leaf length and weight [14]. Therefore, intercropping Chinese chestnut and tea not only improve tea production but also has ecological benefits, representing a sustainable means of tea plantation management [15].
Baohong tea [Camellia sinensis (L.) O. Kuntze cv. Baohong] is the only small-leaf tea grown in Yunnan province, China. It is usually made into a green tea with a unique natural floral aroma; this high-aroma green tea is considered to be almost comparable to the Longjing tea of Hangzhou, China. Since 1965, Baohong tea plants were cultivated over nearly 40 ha on Baohong Mountain in Yiliang county, Yunnan Province. However, in that era of relatively low economic and social development, the income from selling Baohong tea alone was relatively low. Chinese chestnut is also a traditional woody crop in the local area. Therefore, a group of Chinese chestnut trees was also planted in approximately 10 ha of the Baohong tea plantation in the 1970s. In Yiliang, Chinese chestnuts are harvested beginning at about 5 years after cultivation, the market for Chinese chestnut was strong, and the presence of chestnut did not affect the growth of the tea plants. The doubled income from a single piece of land increased tea farmers' profitability, so another group of Chinese chestnuts was added to the Baohong tea plantation $(\sim 10 \mathrm{ha})$ in the 1980s and 1990s, respectively. In the late $1990 \mathrm{~s}$, as the worldwide tea consumption increased, pure tea plantations also become profitable, and the Baohong tea plantation did not plant additional trees on its remaining few hectares. Irrigation and fertilization of tea plants on Baohong Mountain are systematically managed, and the plants were trimmed once a year to ensure that their height was maintained at approximately $1 \mathrm{~m}$. After decades of development, these cultivation systems, including both the pure tea system and the Chinese chestnut-tea intercropping system, have been preserved till the present day, becoming a model for Chinese chestnut-tea intercropping around Kunming and even across China. Although the ecological and economic benefits of Chinese chestnut-tea intercropping have been clearly demonstrated in the Baohong tea plantations, however, it is unclear whether intercropping leads to improved tea quality, as fresh tea leaves from all the Baohong production systems have traditionally been picked and mixed together.

The tea quality is assessed based on the content of characteristic sensory substances, including amino acids, organic acids, sugars, lipids, as well as some bioactive substances like phenolics [16]. Amino acids contribute to the flavor of green tea and confer some health benefits, such as anti-inflammatory, anti-microbial, and positive neurological effects [17]. Organic acids, which also have great health benefits, can affect tea quality due to the taste and their biological activities [16]. Free sugars are essential for catechin synthesis, which can help the formation of tea flavors during processing [16]. Various forms of lipid present in tea leaf that can be altered by heat or oxidation during processing, can generate volatile compounds and result in the characteristic taste of 
green tea [18]. Therefore, effectively and accurately characterizing the dynamics of these complicated chemical substances in tea leaf is required for tea quality assessment. Thus far, a few research have demonstrated that the chestnut-tea intercropping system could improve tea quality by the measuring of one class or a small number of chemical substances in the tea leaf, which cannot fully reflect the complexities of tea quality.

Metabolomics technology provides a more comprehensive approach for measuring the complicated chemical components in tea [19]. Thus far, the effects of Chinese chestnut-tea intercropping on the metabolomics profiling of fresh tea have not been investigated. Systemic characterization of tea composition could be lay the foundation for further improve the quality of green tea through agronomic practice and tea plantation management. Hence, we investigated the effects of Chinese chestnut-tea intercropping systems on tea quality by performing sensory evaluation and measurements of major green tea components and by documenting differences in green tea metabolites through targeted and non-targeted metabolomics with LC-MS. We identify more than 100 differential metabolites were upregulated in the tea leaves from intercropping system relative to monoculture system. Pathway analysis suggests the lavone and flavonol biosynthesis and phenylalanine metabolism, and amino acid metabolism are significantly altered, suggesting that the intercropping of Chinese chestnut-tea could greatly influence allantoic acid, sugars, sugar alcohols, and oleic acids, and amino acid metabolism in tea plants, which are are positively related to improved tea taste. Our results supply a theoretical foundation for developing the ecological model of intercropping with Chinese chestnut and even with other tree species.

\section{Methods}

\section{Plant materials and growth conditions}

The Baohong tea plants were planted in the 1960s on the Baohong mountain, belonging to Baohong Tea Industry Co. LTD, China. The mountain is located at an average elevation of about $1900 \mathrm{~m}$ and has a northern semi-tropical monsoon climate with an average atmospheric temperature of $16.3^{\circ} \mathrm{C}$ and average humidity of $80 \%$. The sampling was conducted on private land, and we confirm that the land owner gave permission for this. We collected four groups, three from tea plants in the chestnut-tea intercropping system planted in the 1970s, 1980s, and 1990s, and one from the pure tea plantation, which served as the control (Table S1). The groups were designated $70 \mathrm{~T}, 80 \mathrm{~T}, 90 \mathrm{~T}$ and $\mathrm{T}$. A bud and two leaves were carefully collected from a tea plant by hand on March 24, 2019. The tea plant covered by the chestnut crown was sampled in the chestnut-tea intercropping system. We took 150 plants in total, dividing them into groups of 50 plants and regarding each group as a biological replicate, and then picked 5 to 10 buds and leaves from each plant. This was done completely at random. This was done completely at random. For each biological replicate of each group, we divided the leaves into two portions. For each biological replicate, all the leaves from 50 plants were placed in a same bamboo bag and then divided into two portions. One portion was placed in a sampling tube, then quick-frozen and temporarily stored in liquid nitrogen, taken to the laboratory, and stored in a freezer at $-80^{\circ} \mathrm{C}$ for targeted and non-targeted metabolomics measurements. The other portion was taken to the Baohong tea processing workshop, where it was steamed in an electric steamer for $4 \mathrm{~min}$. After steaming, the tea leaves were thinly spread on a bamboo mat and dried under the sunshine outdoors for about $4 \mathrm{~h}$. It was performed from 1 to 5 p.m. of March 24, with the temperature from 25 to $23^{\circ} \mathrm{C}$, the wind of SW $12.3 \sim$ $17.7 \mathrm{mph}$, and the solar radiation $682 \mathrm{~kJ} / \mathrm{m}^{2}$. The dried tea leaves were sealed in a self-sealing bag for sensory evaluation and measurement of caffeine, tea polyphenols and free amino acids.

\section{Sensory evaluation of tea samples}

Tea sensory evaluation was carried out by the National Standards of the People's Republic of China (GB/T 23776-2018) via a trained panel of five senior teatasters. It was performed to establish preference rating for appearance, the color of tea liquid, scent, taste, and infused leaf, and be graded according to 20, 20, 25, 25, and 10 score respectively, which means the higher the evaluation, the higher the score. Each sub-item was graded separately, and they were summed up at last as the final score. The blind evaluation system was adopted: that is, the tea-tasters knew nothing about what each tea sample was and could only get the tea sample number. They were supplied with a prescribed questionnaire to document their sensory evaluations. The sensory evaluation was conducted in a room with $25^{\circ} \mathrm{C}$ and a humidity of $67 \%$.

\section{Determination of caffeine content, tea polyphenols and free amino acids}

Caffeine was determined by the National Standards of the People's Republic of China (GB/T 8312-2013) using HPLC (High-Performance Liquid Chromatography). The standard curve was drawn as $\mathrm{y}=32.064 \mathrm{x}-8.2625\left(R^{2}=\right.$ 0.9999). A part of the solution was filtered through the filter membrane of $0.45 \mu \mathrm{m}$, and the liquid was accurately measured and injected into the HPLC and compared with the standard curve.

The determination of tea polyphenols was conducted by the National Standards of the People's Republic of 
China (GB/T 8313-2008). According to the absorbance and concentration of the gallic acid working solution, the standard curve $y=0.005 x+0.0728\left(R^{2}=0.997\right)$ was drawn. Absorption was determined at $765 \mathrm{~nm}$ using Ultraviolet-visible spectroscopy (UV-2401, Shimadzu).

Amino acids were detected by the method of the National Standards of the People's Republic of China (GB/ $T$ 8314-2013). A standard curve was drawn according to the absorbance and the concentration of theanine, which was $y=2.7841 \mathrm{x}-0.1534\left(R^{2}=0.9929\right)$. The absorbance of the sample was determined using the reagent solution as blank control, and the amino acid content was obtained by comparison with the standard curve.

\section{Non-targeted metabolomics}

The non-targeted metabolomics method was performed following the procedure as reported by Zeng et al. [20]. Briefly, metabolites were extracted for the UHPLCQTOF-MS analysis. LC-MS/MS analyses were conducted by UHPLC system (1290, Agilent Technologies)

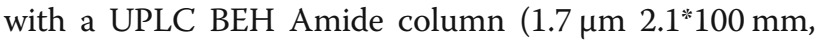
Waters) coupled to TripleTOF 6600 (Q-TOF, AB Sciex). MS unprocessed data files were transformed to the mzXML format by ProteoWizard, and processed by $\mathrm{R}$ package XCMS (version 3.2). The preprocessing results created a data matrix containing the retention time (RT), mass-to-charge ratio $(\mathrm{m} / \mathrm{z})$ values, and peak intensity. $\mathrm{R}$ package CAMERA was applied for peak annotation after XCMS data processing. A second mass spectrometer (MS2) database was used in metabolites identification. The metabolites with the qualitative analysis with MS2 were selected, which were discovered depending on the metabolome databases of HMDB, PubChem, KEGG and METLIN.

\section{Targeted metabolomics}

The analytical methods of targeted amino acids mainly referred to the instruction by $\mathrm{Zhu}$ et al. [21]. The UHPLC separation was performed by Agilent 1290 Infinity II series UHPLC System (Agilent Technologies), furnished with Waters ACQUITY UPLC BEH Amide column $(100 \times 2.1 \mathrm{~mm}, 1.7 \mu \mathrm{m})$. The temperature of the column and auto-sampler was set respectively at $35^{\circ} \mathrm{C}$ and $4{ }^{\circ} \mathrm{C}$. An Agilent 6460 triple quadrupole mass spectrometer (Agilent Technologies) with AJS electrospray ionization (AJS-ESI) interface, was used as assay development. MRM data were collected and processed by Agilent Mass Hunter Work Station Software (B.08.00, Agilent Technologies). The level was eliminated from the calibration if $\mathrm{S} / \mathrm{N}$ (signal-to-noise ratio) was less than or equal to 20 or accuracy of the calibration was beyond $80-120 \%$.

\section{Statistical analyses}

In order to achieve an outline of the figures of chemical variation in the $80 \mathrm{~T}$ and $\mathrm{T}$ samples, the significant differences were investigated by PCA pattern recognition with SIMCA software (V14.1, Sartorius Stedim Data Analytics AB, Umea, Sweden). To get a higher level of group separation and a better understanding of $\mathrm{T}$ and $80 \mathrm{~T}$ samples liable for categorization, supervised OPLSDA were used. Metabolites (VIP > 1.0) were supposed as vital metabolites for potential discrimination of samples in the OPLS-DA models. We used the Student's test, which is commonly used for metabolomics statistical analysis. $P<0.05$ in the Student's test was supposed statistically significant.

\section{Results}

Green tea from the intercropping of chestnut cultured in the 1980s ranked highest in sensory evaluation

$80 \mathrm{~T}$ received the highest sensory evaluation among the four green tea samples. The taste scores of $70 \mathrm{~T}, 80 \mathrm{~T}$ and $90 \mathrm{~T}$ were $88.5,91$ and 81.5, respectively (Table S2). $80 \mathrm{~T}$ was fresh, exhibited a strong aroma, and had the best taste. $70 \mathrm{~T}$ was fresh and tender and had an aroma. The taste of $\mathrm{T}$ sample was described by the tea-taster as pure and normal with a clean flavor, and its score was 82.5. These results indicated that Chinese chestnut-tea intercropping had a positive impact on the taste and aroma of Baohong green tea, especially for the tea grown with Chinese chestnuts planted in the 1980s.

\section{Green tea from the intercropping of chestnut cultured in} the 1980s had the lowest polyphenol:amino acid ratio

Amino acid content is higher and polyphenol content is lower in Baohong green tea from the intercropping system, leading to a lower ratio of tea polyphenols to amino acids, particularly in the $80 \mathrm{~T}$ sample. This low ratio is often considered to be a good indicator of green tea quality [22]. This result is consistent with the sensory evaluation results, which indicated that $80 \mathrm{~T}$ green tea had the best taste. As shown in Fig. 1, the tea polyphenol contents of $70 \mathrm{~T}, 80 \mathrm{~T}$ and $90 \mathrm{~T}$ were $19.28,18.73$ and $16.48 \%$, respectively, and lower than that of the $\mathrm{T}$ control sample (21.09\%). Likewise, their caffeine contents were 2.19, 2.12 and $2.15 \%$, again lower than that of the T sample (2.22\%).

The $80 \mathrm{~T}$ sample was selected as the intercropping sample for the subsequent metabolomics analysis compared with the monoculture sample because $80 \mathrm{~T}$ sample received the highest sensory evaluation and had the most appropriate levels of major tea chemical components.

\section{Metabolite profiles differed under the intercropping vs. monoculture}

Figure 2 presents base peak intensity (BPI) chromatograms in positive and negative ionization modes for the 

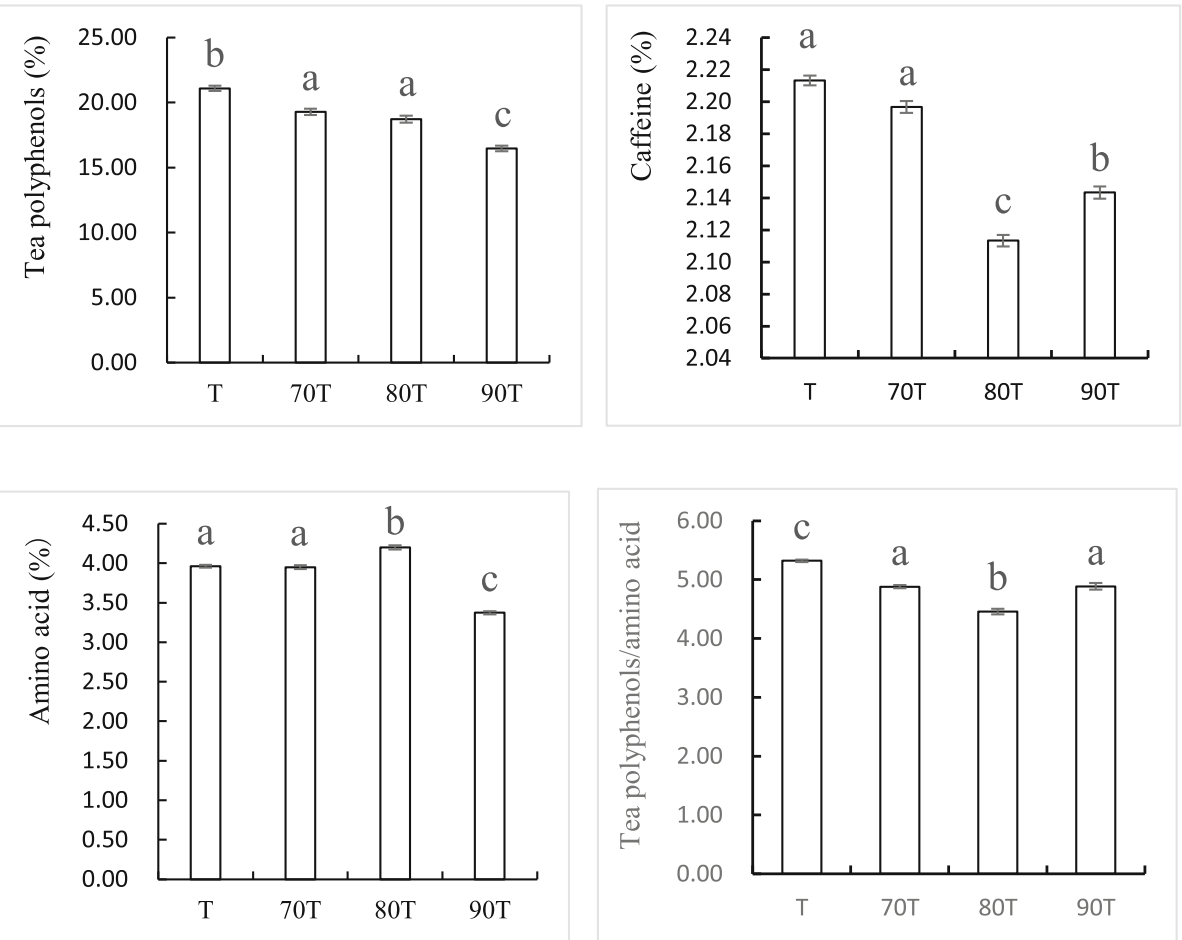

Fig. 1 Detection of major components of steamed green tea of T, 70 T, 80 T and $90 \mathrm{~T}$

samples under the intercropping vs. monoculture. Metabolites differed significantly between samples from the intercropping system and those from the pure tea system. In total, 3450 and 3538 metabolite ion features differed from the two culture systems in the two modes (Figure S1), respectively. A volcano plot (Fig. 2) showed that there were more upregulated than downregulated metabolites under the intercropping vs. monoculture, suggesting the intercropping not only caused differences in metabolites but also promoted metabolite accumulation.
OPLS-DA models all showed a great goodness-of-fit $\left(R^{2} \mathrm{X}\right)$ and high predictability $\left(Q^{2}\right)$, with 0.478 and 0.728 in positive mode (Fig. 3a) and 0.445 and 0.746 in negative mode (Fig. 3c) for the samples under the intercropping vs. monoculture. The OPLS-DA models were confirmed by response permutation testing (RPT), disclosing the absence of overfitting (Fig. 3b and d) and discovered no false positives in our data. PCA score plots indicated that the metabolic profiles of tea leaves under the intercropping vs. monoculture differed markedly.

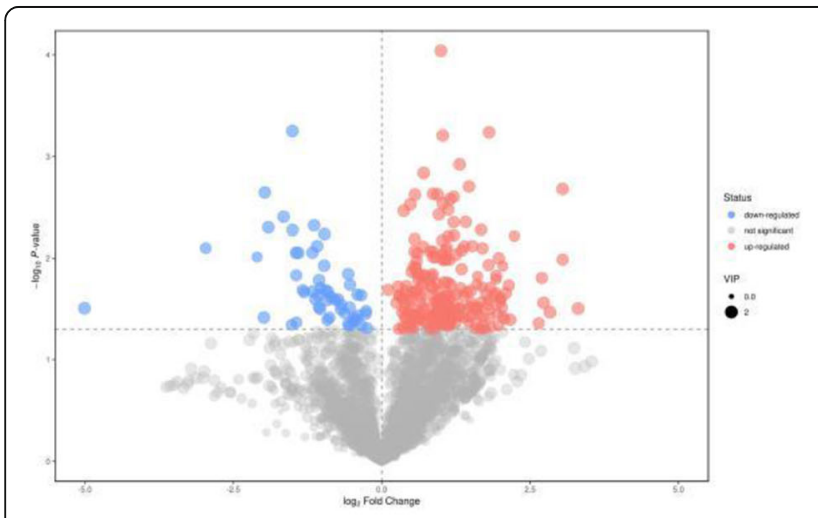

A

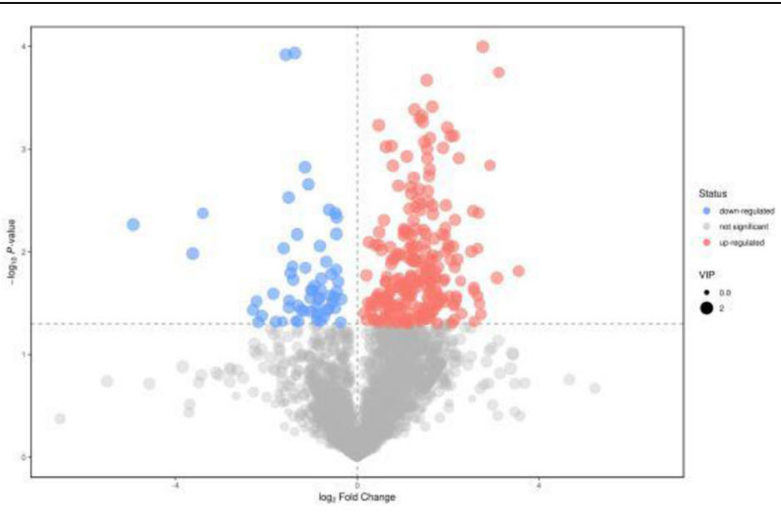

B

Fig. 2 The volcano plots of positive (a) and negative (b) modes based on the non-target metabolomics in the tea samples of $80 \mathrm{~T}$ (intercropping) vs. T (monoculture) 


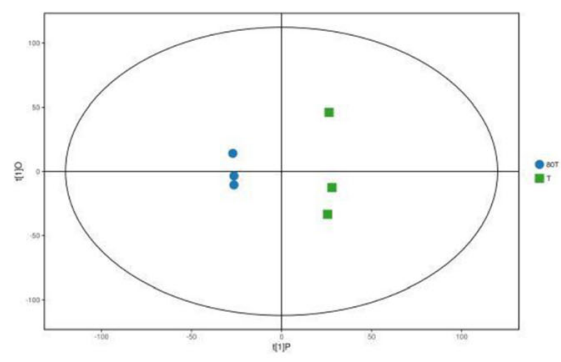

A

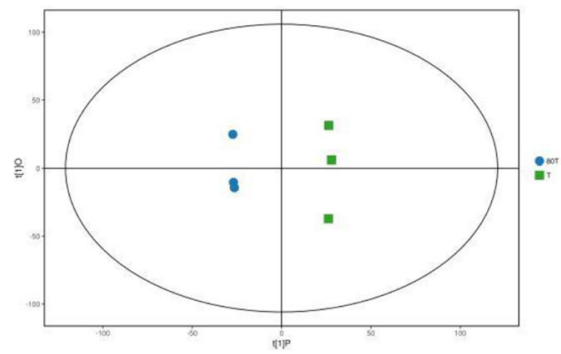

C

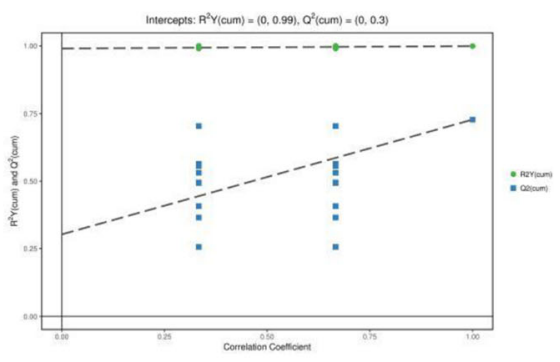

B

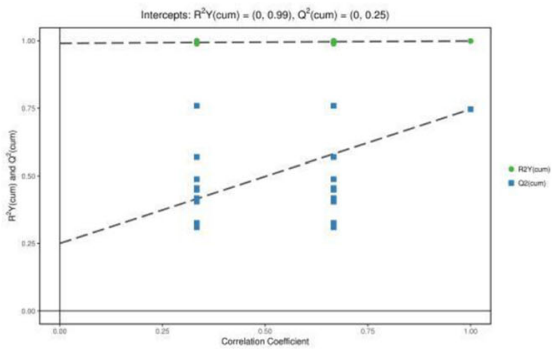

D

Fig. 3 OPLS-DA models based on the non-target metabolomics for the data from positive $(\mathbf{a}, \mathbf{b})$ and negative (c, $\mathbf{d})$ ionization modes for the tea samples of $80 \mathrm{~T}$ (intercropping) vs. T (monoculture): score plots (a, $\mathbf{c}$ ) and permutation plots (b, d)

Four-component PCA score plots were established for the data from both positive modes $\left(R^{2} \mathrm{X}=0.99, Q^{2}=0.3\right)$ and negative modes $\left(R^{2} \mathrm{X}=0.99, Q^{2}=0.25\right)$. All samples were in the $95 \%$ confidence interval (Hotelling's $t$ squared ellipse).

\section{Numerous metabolites with MS2 identifications differed under the intercropping vs. monoculture}

A total of 100 metabolites with MS2 identifications, 65 in positive mode and 35 in negative mode, differed significantly under the intercropping vs. monoculture (VIP>1.0 and $P<0.05$ ) depending on the HMDB, PubChem, KEGG and METLIN metabolome databases. The differential metabolites could be sorted as amino acids, organic acids, carbohydrates, lipids and flavonoids (Table 1). These are flavor compounds, bioactive components, or compounds that release volatiles during tea manufacturing and are considered to be aroma precursors [23]. They are the most important basic materials in fresh tea leaves that determine tea quality. Heat maps were constructed to acquire an obvious outline of metabolites between the samples (Fig. 4). The differential metabolites could clearly be divided into up- and downregulated groups, and the majority (68\%) were upregulated.

To better understand the relationship between tea metabolites and tea quality in the intercropping system, we discussed the major classes of differential metabolites in detail below.

\section{Amino acids}

Eleven upregulated and four downregulated amino acids were identified under the intercropping vs. monoculture based on non-targeted metabolomics. Interestingly, theanine was upregulated in two modes, [1.06-fold in positive mode (VIP $=0.69$ and $P=0.54$ ) and 1.48 -fold in negative mode (VIP $=0.94$ and $P=0.40$ )], although it did not satisfy the statistical conditions of VIP $>1.0$ and $P<$ 0.05 . Theanine is the most abundant and important in tea and primarily responsible for its umami taste [24]. Differences in theanine were not statistically significant, suggesting that the taste improvement associated with intercropping was not dependent on theanine. The role of theanine in taste perception is not denied here, but it only showed there were minor differences in theanine content between the intercropping system and the pure tea plantation.

To verify the contents of free amino acids-and also because of the vital role of free amino acids to the savory taste of tea-we further performed an in-depth analysis of free amino acids using targeted metabolomics on the same samples used for non-targeted metabolomics.

Targeted metabolomics identified 21 upregulated and three downregulated amino acids under the intercropping vs. monoculture showed in Table 2 and Fig. 5a. 
Table 1 Differential metabolites with MS2 based on the non-target metabolomics in the tea samples of 80 T (intercropping) vs. T (monoculture). 1A Metabolites in positive modes. 1B Metabolites in negative modes

\begin{tabular}{|c|c|c|c|c|c|}
\hline Classification & MS2 name & RT & VIP & $P$ value & Fold change \\
\hline \multicolumn{6}{|l|}{$1 \mathrm{~A}$} \\
\hline \multirow[t]{13}{*}{ Amino acids } & L-Valine & 338.138 & 1.12 & 0.05 & 3.59 \\
\hline & L-Phenylalanine & 239.997 & 1.72 & 0.03 & 1.19 \\
\hline & cis-4-Hydroxy-D-proline & 340.546 & 1.77 & 0.03 & 1.30 \\
\hline & Acetylglycine & 356.8465 & 1.17 & 0.05 & 3.17 \\
\hline & Isobutyrylglycine & 49.179 & 1.24 & 0.01 & 4.70 \\
\hline & DL-Homocystine & 298.929 & 1.64 & 0.02 & 2.39 \\
\hline & L-Erythro-4-Hydroxyglutamic acid & 394.8715 & 1.59 & 0.03 & 2.20 \\
\hline & Tyramine & 239.973 & 1.75 & 0.02 & 1.23 \\
\hline & Theanine & 300.140 & 0.70 & 0.54 & 1.06 \\
\hline & N2-Acetyl-L-ornithine & 340.1385 & 1.68 & 0.04 & 0.74 \\
\hline & Dimethylglycine & 314.045 & 1.74 & 0.02 & 0.75 \\
\hline & Glutathione disulfide & 475.8755 & 1.80 & 0.03 & 0.60 \\
\hline & L-Alanine & 365.347 & 1.85 & 0.01 & 0.68 \\
\hline \multirow[t]{6}{*}{ Organic acids } & Urocanic acid & 311.8865 & 1.69 & 0.02 & 1.56 \\
\hline & Xanthurenic acid & 206.8875 & 1.65 & 0.02 & 1.92 \\
\hline & Allantoate/Allantoic acid & 343.072 & 1.22 & 0.04 & 3.13 \\
\hline & Biliverdin & 111.658 & 1.97 & 0.02 & 2.81 \\
\hline & Mevalonic acid & 322.165 & 1.99 & 0.03 & 0.03 \\
\hline & Kynurenic acid & 172.561 & 1.88 & 0.01 & 0.44 \\
\hline \multirow[t]{3}{*}{ Lipids } & Jasmine lactone & 277.9675 & 1.76 & 0.02 & 1.21 \\
\hline & Stearoylcarnitine & 139.053 & 1.85 & 0.01 & 1.47 \\
\hline & Dodecanoic acid & 77.1265 & 1.75 & 0.02 & 0.79 \\
\hline \multirow[t]{5}{*}{ Carbohydrates } & L-Rhamnose & 316.302 & 1.22 & 0.03 & 2.70 \\
\hline & Maltopentaose & 493.523 & 1.67 & 0.05 & 1.30 \\
\hline & D-Xylose & 56.531 & 1.79 & 0.02 & 1.49 \\
\hline & Ribitol & 163.045 & 1.78 & 0.02 & 1.33 \\
\hline & L-Iditol & 114.379 & 1.53 & 0.04 & 1.40 \\
\hline \multirow[t]{6}{*}{ Flavonoids } & Apiin & 331.713 & 1.76 & 0.01 & 1.64 \\
\hline & Luteolin & 327.191 & 1.53 & 0.02 & 3.03 \\
\hline & Apigenin & 181.574 & 1.16 & 0.01 & 0.23 \\
\hline & Naringin & 175.755 & 1.90 & 0.01 & 0.51 \\
\hline & Prunasin & 52.481 & 1.86 & 0.01 & 0.47 \\
\hline & Gentisaldehyde & 323.015 & 1.73 & 0.03 & 0.62 \\
\hline \multicolumn{6}{|l|}{$1 \mathrm{~B}$} \\
\hline \multirow[t]{5}{*}{ Amino acids } & N-Acetyl-L-alanine & 251.6825 & 1.97 & 0.00 & 2.13 \\
\hline & L-Glutamate & 407.621 & 1.78 & 0.02 & 1.15 \\
\hline & L-Histidine & 208.502 & 1.57 & 0.03 & 4.33 \\
\hline & gamma-L-Glutamyl-L-valine & 351.7275 & 1.71 & 0.03 & 1.61 \\
\hline & Theanine & 298.777 & 0.94 & 0.40 & 1.48 \\
\hline \multirow[t]{3}{*}{ Organic acids } & Malonic acid & 374.182 & 1.60 & 0.03 & 1.59 \\
\hline & Succinylacetone & 227.898 & 1.71 & 0.02 & 2.00 \\
\hline & Ethyl glucuronide & 335.646 & 1.81 & 0.01 & 1.68 \\
\hline
\end{tabular}


Table 1 Differential metabolites with MS2 based on the non-target metabolomics in the tea samples of 80 T (intercropping) vs. T (monoculture). 1A Metabolites in positive modes. 1B Metabolites in negative modes (Continued)

\begin{tabular}{|c|c|c|c|c|c|}
\hline Classification & MS2 name & RT & VIP & $P$ value & Fold change \\
\hline & 2-Furoic acid & 285.4685 & 1.88 & 0.01 & 1.45 \\
\hline & 2,3-Dihydroxy-3-methylbutyric acid & 147.616 & 1.98 & 0.00 & 3.95 \\
\hline & Caffeic Acid & 327.572 & 1.88 & 0.02 & 2.68 \\
\hline & L-Dihydroorotic Acid & 143.736 & 1.63 & 0.05 & 2.11 \\
\hline & Galactonic acid & 353.881 & 1.76 & 0.05 & 0.57 \\
\hline & Tartaric acid & 398.58 & 1.79 & 0.02 & 0.67 \\
\hline & 4-Hydroxycinnamic acid & 145.027 & 1.56 & 0.04 & 0.44 \\
\hline & Citric acid & 448.29 & 1.68 & 0.04 & 0.71 \\
\hline & Methylmalonic acid & 445.2185 & 1.92 & 0.01 & 0.73 \\
\hline & Kynurenic acid & 172.775 & 1.98 & 0.00 & 0.45 \\
\hline Lipids & Oleic acid & 40.499 & 1.97 & 0.00 & 1.68 \\
\hline
\end{tabular}

GABA ( $\gamma$-aminobutyric acid) which is a nonprotein amino acid and an important bioactive tea component that provides various health benefits [25], was upregulated 1.62-fold in samples of the intercropping vs. monoculture. Levels of L-alanine (Ala), L-proline (Pro), Phe, L-serine (Ser), and L-glutamine (Gln) were markedly higher under the intercropping vs. monoculture.

Half of the upregulated amino acids had documented roles in improving the flavor of green tea, whereas none of the downregulated amino acids were known to influence tea flavor. Among the upregulated flavor-promoting amino acids, L-methionine (Met), Pro, Ala, L-threonine (Thr), and Ser are sweet-tasting compounds; Glu, Gln, L-asparagine (Asn), and L-aspartic acid (Asp) contribute an umami taste; and Phe and L-glycine (Gly) produce a floral aroma [reviewed in $\mathrm{Yu}$ and Yang] [18]. Asn showed the greatest upregulation in the intercropping (3.30-fold). It is worth noting that amino acids that make the greatest contribution to taste, such as Glu, Asp and Gln, were present at concentrations above $10,000 \mathrm{nmol} / \mathrm{g}$ in the intercropping and therefore provided rich raw materials for producing green tea with high quality in the intercropping system.

To display the upregulated flavor-promoting and bioactive amino acids more intuitively, they are labeled with ovals in Fig. 5b and color-coded according to their properties: sweet in pink, umami in orchid, floral aroma in orange, and bitter and sweet in green. Bioactive amino acids are indicated with a dark red ring, based on the KEGG pathway 'biosynthesis of amino acids' (map01230). The abundant upregulated amino acids in the intercropping suggested that fresh leaves from the intercropping system were more suitable for the production of green tea.

Amino acids downregulated in the intercropping vs. monoculture included 4-hydroxyproline, 1-methyl-L-histidine (1-MHis) and 3-methyl-L-histidine (3-MHis). The recognition threshold for sweetness is lower in 4- hydroxyproline than in other sweet amino acids such as Pro, Ala, and Thr [26]. 1-MHis and 3-MHis have not been reported as taste compounds. Therefore, we speculated that its downregulation in the intercropping may have had little effect on tea sweetness, especially given the upregulation of other sweet amino acids.

\section{Organic acids}

We detected 11 significantly upregulated and seven significantly downregulated organic acids in samples under the intercropping vs. monoculture. The greatest upregulation (3.3-fold) was observed in allantoic acid, the conjugate acid of allantoate. Allantoin and allantoate exist in the caffeine degradation of caffeinecontaining plants; specifically, caffeine is converted to allantoic acid by way of theophylline, 3-methylxantine, xanthine and uric acid [27, 28]. The relative content of allantoin in plant may reflect the caffeine degradation [29]. Therefore, we speculate that caffeine may have been degraded into allantoic acid in the intercropping system, causing accumulation of allantoic acid, consistent with the lower caffeine content measured in the intercropping (Fig. 1).

Xanthurenate (XA) increased and kynurenic acid (KA) decreased in the intercropping samples relative to the $\mathrm{T}$ samples in two modes. XA and KA are both components of the kynurenine pathway of tryptophan degradation [30], as shown in Figure S3. Additional differentially abundant organic acids may have contributed to differences in tea flavor. Malonic and caffeic acid (upregulated) and tartaric and citric acid (downregulated) have all been reported to have a sour taste [31], and changes in their contents may have influenced the differences in flavor between green tea from the intercropping system and the pure tea garden. 


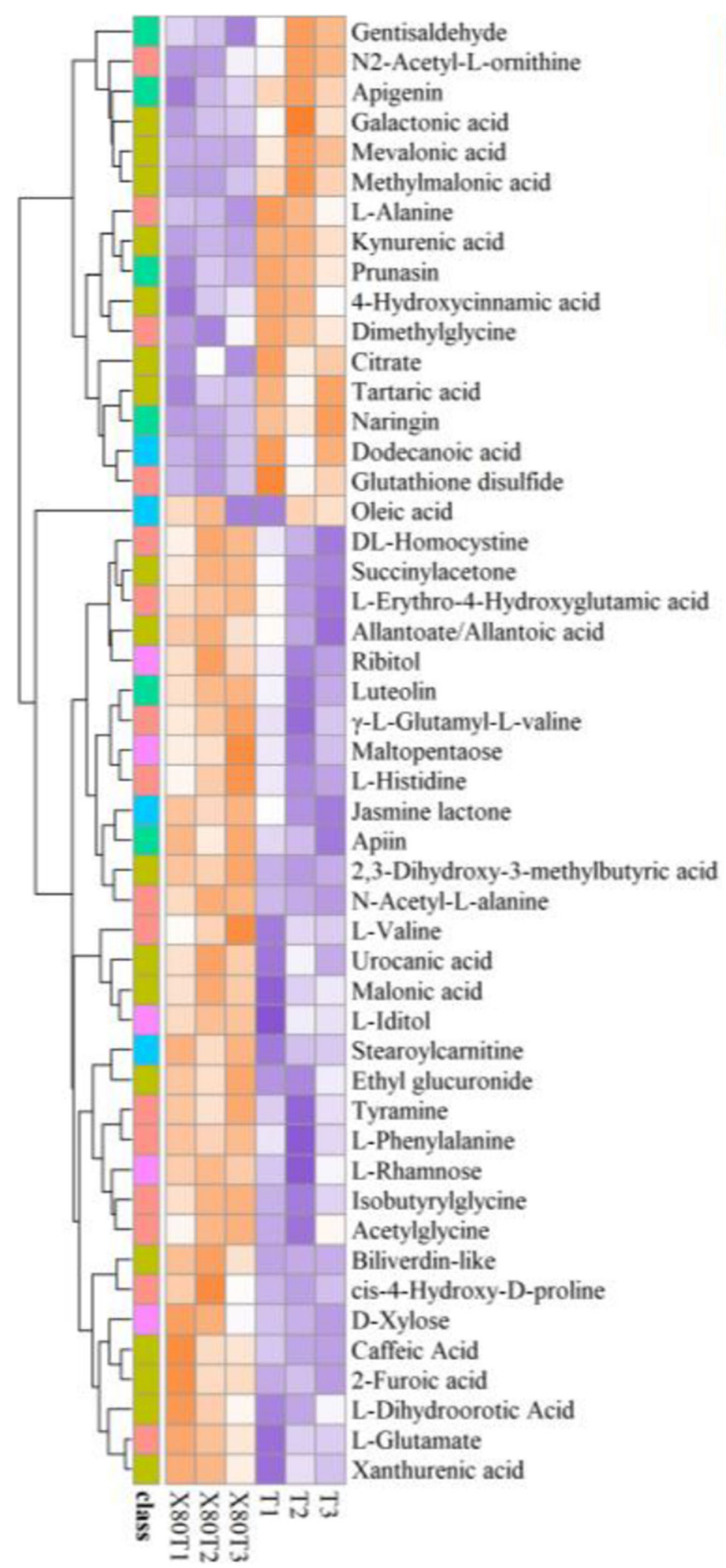

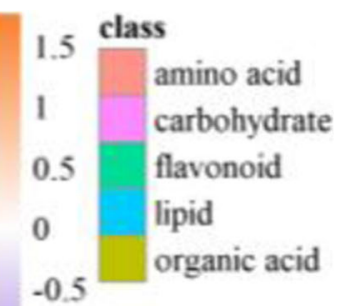

$-1$

$-1.5$ 
Table 2 The amino acids based on the target metabolomics in the tea samples of $80 \mathrm{~T}$ (intercropping) vs. T (monoculture)

\begin{tabular}{|c|c|c|c|c|c|c|c|c|}
\hline Name & Abbreviation & MEAN $80 \mathrm{~T}(\mathrm{nmol} / \mathrm{g})$ & MEAN T (nmol/g) & VIP & $P$ value & Fold change & Log_Fold change & Flavor or not \\
\hline L-Methionine & Met & 77.24 & 60.68 & 1.07 & 0.19 & 1.27 & 0.35 & sweet \\
\hline L-Proline & Pro & 175.52 & 124.45 & 1.19 & 0.15 & 1.41 & 0.50 & sweet, bitter \\
\hline L-Alanine & Ala & 1786.97 & 1375.01 & 1.31 & 0.03 & 1.30 & 0.38 & sweet \\
\hline L-Threonine & Thr & 4539.63 & 3356.81 & 1.31 & 0.09 & 1.35 & 0.44 & sweet \\
\hline L-Serine & Ser & $13,202.69$ & 7802.77 & 0.73 & 0.22 & 1.69 & 0.76 & sweet \\
\hline L-Asparagine & Asn & 3532.84 & 1069.28 & 1.49 & 0.06 & 3.30 & 1.72 & umami \\
\hline L-Glutamic acid & Glu & $18,283.39$ & $12,094.54$ & 0.66 & 0.41 & 1.51 & 0.60 & umami \\
\hline L-Aspartic acid & Asp & $12,427.77$ & 8698.41 & 0.64 & 0.46 & 1.43 & 0.51 & umami \\
\hline L-Glutamine & Gln & $17,306.94$ & 9891.39 & 0.75 & 0.21 & 1.75 & 0.81 & umami \\
\hline L-Phenylalanine & Phe & 293.31 & 291.15 & 0.21 & 0.95 & 1.01 & 0.01 & floral aroma \\
\hline L-Glycine & Gly & 777.64 & 623.06 & 1.11 & 0.17 & 1.25 & 0.32 & floral aroma \\
\hline L-Tryptophan & Trp & 851.86 & 769.41 & 0.70 & 0.57 & 1.11 & 0.15 & bitter \\
\hline L-Arginine & Arg & 3785.44 & 3147.93 & 0.74 & 0.59 & 1.20 & 0.27 & bitter, sweet \\
\hline L-Histidine & His & 2696.35 & 1439.46 & 1.33 & 0.18 & 1.87 & 0.91 & bitter \\
\hline L-Valine & Val & 1319.02 & 1220.96 & 0.61 & 0.75 & 1.08 & 0.11 & bitter, sweet \\
\hline L-Tyrosine & Tyr & 6.37 & 3.61 & 1.29 & 0.06 & 1.76 & 0.82 & bitter \\
\hline L-Lysine & Lys & 783.85 & 470.56 & 1.30 & 0.06 & 1.67 & 0.74 & bitter, sweet \\
\hline 4-Aminobutyric acid & GABA & 1380.00 & 854.07 & 1.54 & 0.01 & 1.62 & 0.69 & no \\
\hline L-Citrulline & Cit & 314.20 & 184.52 & 1.00 & 0.30 & 1.70 & 0.77 & no \\
\hline$\beta$-Alanine & $\beta$-Ala & 15.95 & 7.85 & 1.07 & 0.04 & 2.03 & 1.02 & no \\
\hline L-Ornithine & Orn & 320.31 & 173.38 & 0.39 & 0.69 & 1.85 & 0.89 & no \\
\hline 4-Hydroxyproline & 4-Hyd & 56.33 & 214.33 & 0.90 & 0.37 & 0.26 & -1.93 & no \\
\hline 1-Methyl-L-histidine & 1-Mhis & 107.07 & 237.82 & 0.67 & 0.41 & 0.45 & -1.15 & no \\
\hline 3-Methyl-L-histidine & 3-Mhis & 115.18 & 133.47 & 0.35 & 0.53 & 0.86 & -0.21 & no \\
\hline
\end{tabular}

\section{Carbohydrates}

The sugars rhamnose, maltopentaose and D-xylose and the sugar alcohols ribitol, L-iditol and D-threitol were all upregulated in samples under the intercropping vs. monoculture. Rhamnose showed the greatest upregulation (2.7-fold). D-maltopentaose, upregulated 1.30-fold, is an oligosaccharide with low sweetness that is widely used in the food industry and has applications in nutrition and healthcare [32]. D-xylose, a dextrorotary form of xylose, was upregulated 1.49-fold; it is widely used as a diabetic sweetener in foods and beverages and is much sweeter than D-glucose [33], suggesting that it may have a role in the improvement of tea taste.

Sugar alcohols were also increased by various amounts in samples under the intercropping vs. monoculture, and the most strongly upregulated was D-threitol (2.21-fold). Ribitol, also called adonitol, was upregulated 1.33-fold; it is formed by the reduction of ribose in certain plants and contributes to the structure of riboflavin [34]. Liditol, upregulated 1.40 -fold, is a hexitol with a sweet taste that has applications in the food industry. Most sugar alcohols are less sweet than sucrose. However, they also have less food energy, which is particularly important for human health in the present era of excess food and calories $[35,36]$.

Overall, increased carbohydrates with varying degrees of sweetness and different tastes may have provided raw materials to make green tea brewed from the intercropping samples sweeter and richer, with a better taste.

\section{Lipids}

Jasmine lactone, oleic acid and stearoyl carnitine were upregulated in samples under the intercropping vs. monoculture, and only dodecanoic acid was downregulated. Jasmine lactone and oleic acid upregulated 1.21fold and 1.68-fold, respectively.

\section{Flavonoids}

Flavonoids were detected only in the positive mode; two were significantly upregulated and four were significantly downregulated. Apiin increased 1.76-fold, whereas apigenin decreased 1.16-fold. Apiin (apigenin 7-O-apioglucoside) is a water-soluble diglycoside of the more hydrophobic apigenin [37], and tea from the intercropping may provide more water-soluble apiin when consumed. More importantly, apiin has no taste, 


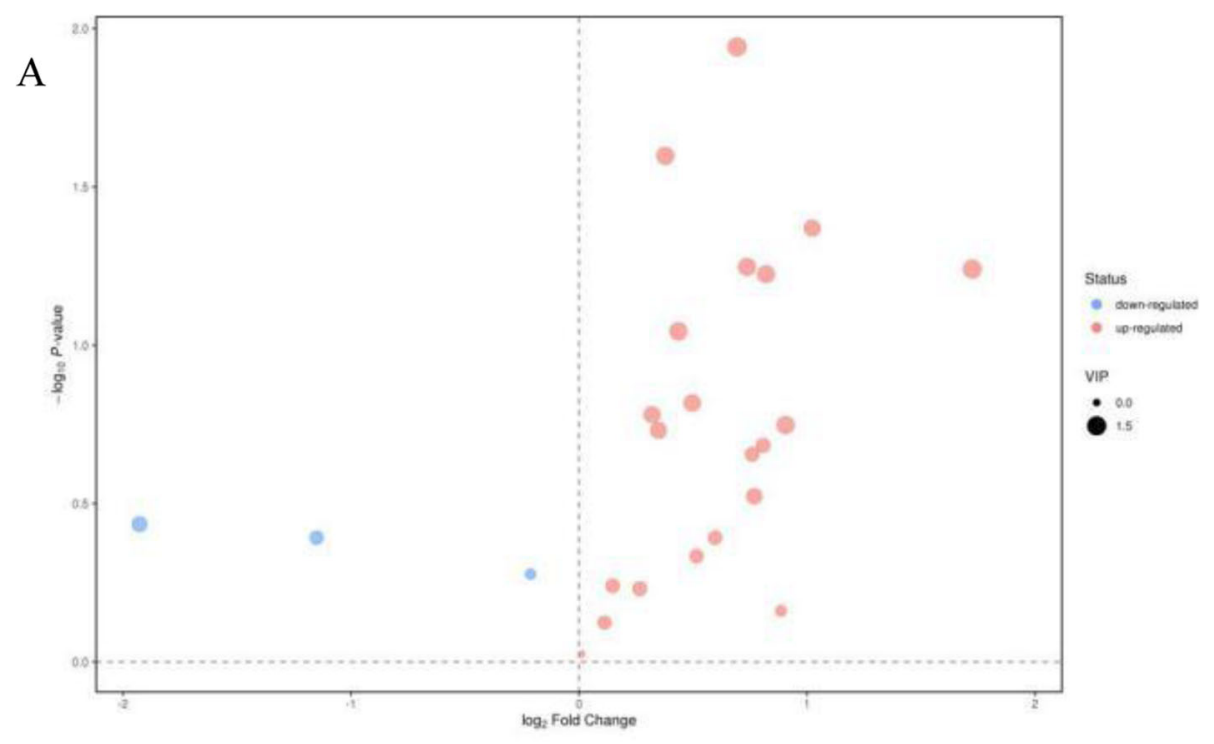

B

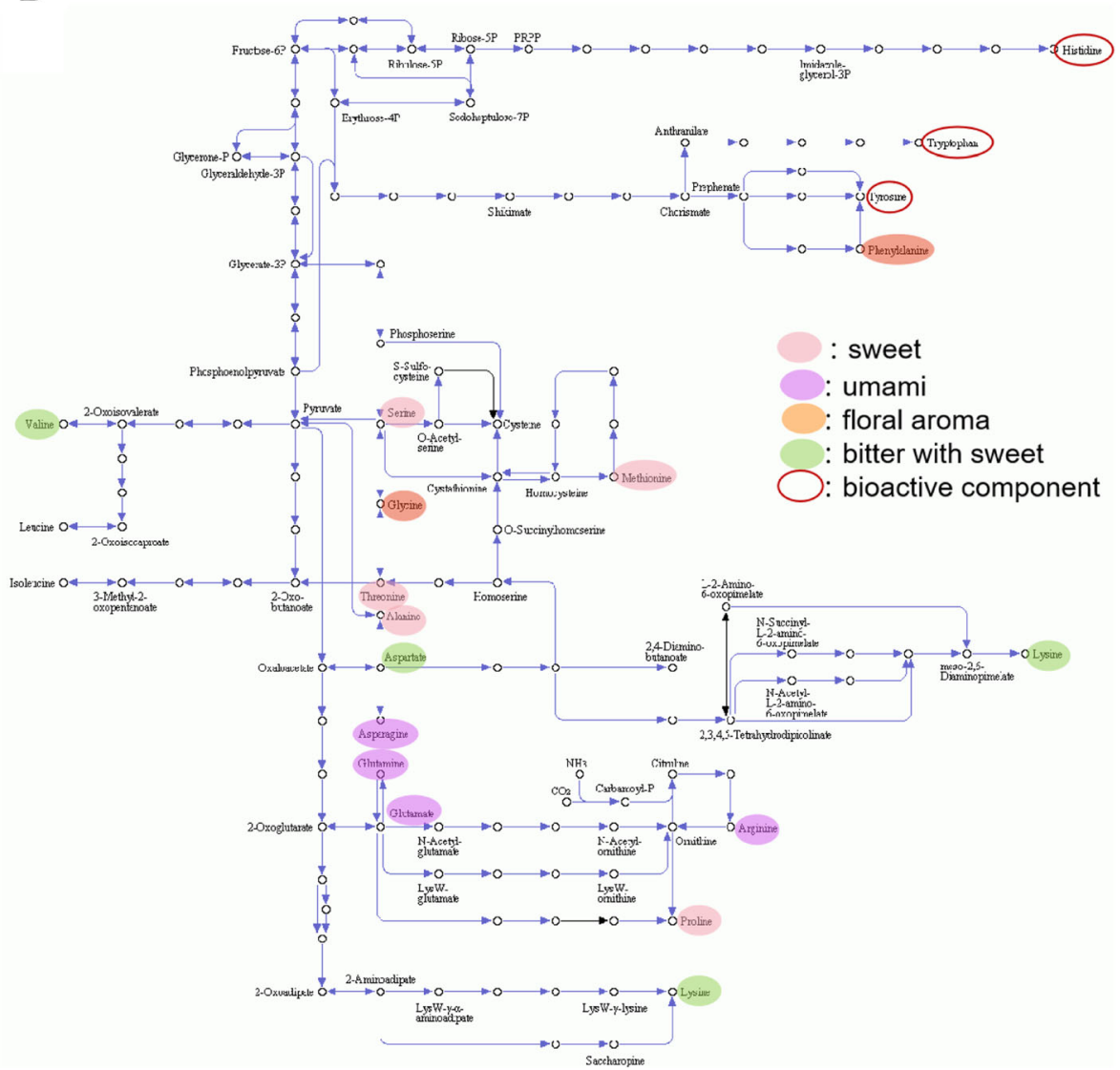

Fig. 5 Volcano plot (a) and the up-regulated amino acids on the metabolomics in biosynthesis of amino acids (map01230) (b) for $80 \mathrm{~T}$ (intercropping) vs. T (monoculture) based on the target metabolomics

whereas apigenin is bitter: increased apiin and decreased apigenin should therefore reduce the bitterness of brewed tea, increasing its palatability. Additional downregulated flavonoids included naringin and prunasin. Luteolin was upregulated 1.53-fold in samples under the intercropping vs. monoculture. Taken together, our results indicated that the intercropping samples vs. $\mathrm{T}$ had lower amounts of the bitter 


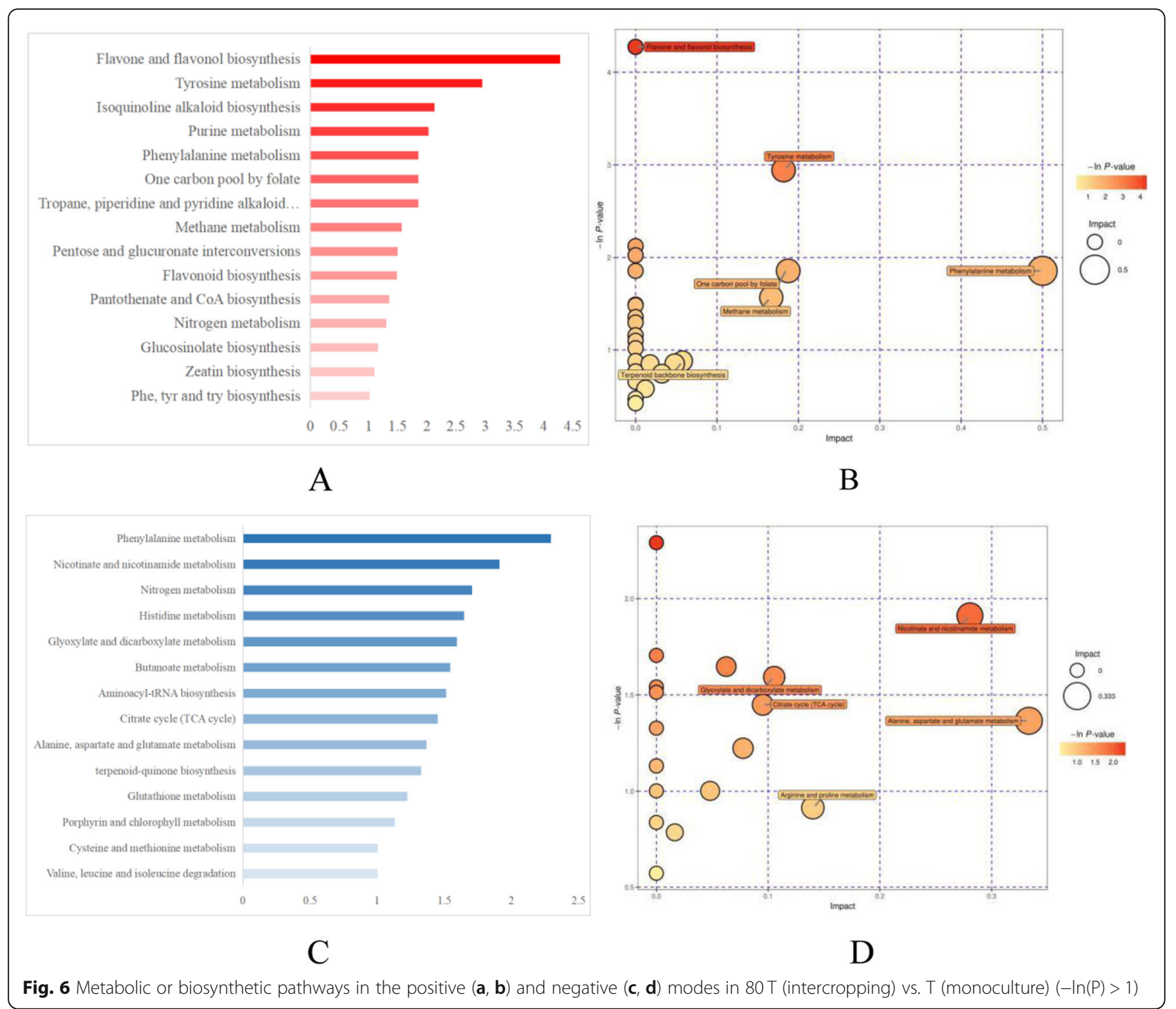

compounds apigenin, naringin and prunasin and greater amounts of the tasteless compound apiin, consistent with the better taste of their tea.

\section{Secondary metabolite pathway analysis}

The differentially abundant metabolites mapping to the KEGG database displaying in Fig. 6, 15 metabolic or biosynthetic pathways (Fig. 6a, b) showed differences in positive mode and 14 (Fig. 6c, d) in negative mode for samples under the intercropping vs. monoculture $(-\ln (\mathrm{P})>1)$.

In positive mode, the flavone and flavonol biosynthesis pathway showed the greatest degree of alteration. Upregulated apiin and luteolin and downregulated apigenin are involved in this biosynthetic pathway, and apiin and luteolin are located downstream of apigenin, suggesting that the enzymes of apiin and luteolin biosynthesis were activated in the intercropping system. Luteolin and apigenin are also involved in flavonoid biosynthesis. In addition, naringin was also downregulated. In addition, Val and Phe appeared to have important roles: together they participated in four pathways, including cyanoamino acid metabolism, aminoacyl-tRNA biosynthesis, 2oxocarboxylic acid metabolism, and biosynthesis of amino acids. Sugars and sugar alcohols were mainly involved in pentose and glucuronate interconversions and $\mathrm{ABC}$ transporters.

In negative mode, the Phe metabolism pathway showed the largest difference between intercropping and monoculture. Plants synthesize types of volatile organic compounds to interact with the surrounding environment via Phe metabolism [38]. The products of this pathway are not immediately needed for cell survival but can increase the fitness of the plant as a whole. In our study, eight differentially abundant metabolites were 
involved in Phe metabolism. Phe itself took part not only in phenylalanine metabolism but also in four other pathways, highlighting its multiple functions and versatility. Some Phe-related metabolites were also conducive to the formation of fragrance: phenylpyruvic acid has a slight honey-like odor, trans-cinnamic acid has a light cinnamon aroma, and phenylacetaldehyde has a strong fruity, nut-like, floral and sweet scent. Together, these metabolites provide abundant raw materials for the production of green tea aromas. Finally, phenylethylamine is a neurotransmitter that raises the level of dopamine in extracellular fluids, making people feel more positive and satisfied; its presence could explain why tea drinking can improve the mood to some extent.

Glu and His appeared together in the four of the top 10 differentially expressed pathways identified in the negative mode, suggesting that they have multiple functions. Glu participated individually in alanine, aspartate and glutamate metabolism; carbon metabolism; 2-oxocarboxylic acid metabolism; and glyoxylate and dicarboxylate metabolism. Likewise, His participated individually in beta-alanine metabolism.

Five pathways showed significant differences in both the positive and negative modes: biosynthesis of amino acids, aminoacyl-tRNA biosynthesis, carbon metabolism, 2-oxocarboxylic acid metabolism, and $\mathrm{ABC}$ transporters. The numbers of pathways associated with amino acid metabolism in both the positive and negative modes were remarkably high: five pathways (biosynthesis of amino acids; arginine and proline metabolism; glycine, serine and threonine metabolism; tyrosine metabolism; and tryptophan metabolism) were defined in two modes, and four pathways (biosynthesis of amino acids; alanine, aspartate and glutamate metabolism; histidine metabolism; and beta-alanine metabolism) were identified in the negative mode only. This result suggests that the intercropping system significantly affected amino acid metabolism and thereby altered the accumulation and degradation of amino acids. Combined with the results of the targeted amino acid metabolomics, these results indicated that amino acids with a good taste accumulated in leaves under intercropping compared with monoculture, whereas flavorless amino acids were less abundant.

\section{Discussion}

\section{Up-regulated delicious amino acids may be the raw material of delicious green tea, while the down-regulated are less responsive to the flavor}

Free amino acids contribute to the taste of tea, and taste intensity increases with increasing amino acid concentration $[39,40]$. Twenty-nine amino acids were identified in green tea extracts in previous studies, and 11 Amino acids are responsible for the quality of tea infusion and antioxidant and anti-inflammatory functions [12, 41].
Combinations of amino acids with their individual special tastes could expand the possibilities for new tea tastes or functions. For instance, Asp has a sour, slightly umami taste, whereas Phe is tasted a little bitter. Whereas, aspartame which is a conjugate of these two amino acids, is 200 times sweeter than sugar [42]. The simultaneous increase of Asp and Phe could provide a basis for greater aspartame production. Together, our results suggest that upregulation of multiple sweet, umami and floral amino acids in the intercropping samlpes may be the proximate cause of its excellent flavor in green tea.

The bitter-tasting amino acids arginine (Arg), Val, lysine (Lys), tryptophan (Trp), tyrosine (Tyr), and His were also differentially abundant between samples under the intercropping vs. monoculture. These six bitter amino acids can be further classified into two subcategories: Arg, Val, and Lys contribute both bitter and sweet flavors, whereas Tyr, Trp and His are neurotransmitter precursors [43-45]. Due to their important biological activities, the boosts in the contents of these amino acids from intercropping system may increase the health benefits of the resulting tea. Such benefits are another aspect of tea quality.

MHis and 3-MHis are derived primarily from anserine ( $\beta$-alanyl-1-methyl-histidine) and balenine ( $\beta$-alanyl-3methyl-histidine), respectively, and both anserine and balenine have antioxidant functions [46]. The downregulation of 1-MHis and 3-MHis in the intercropping system may have reflected a reduced ability of anserine and balenine to form 1-MHis and 3-MHis, thereby permitting more anserine and balenine to accumulate and perform antioxidant functions. Antioxidants can protect cells by eliminating reactive oxygen species (ROS) [47]. They can also scavenge free radicals in humans if taken in food to treat diseases and protect health [48]. The potential accumulation of anserine and balenine in intercropping tea plants requires further experimental investigation and may provide new evidence for the antioxidant effects of tea.

\section{Up-regulated GABA may be responsive to the increased bioactivity of green tea}

GABA is an important inhibitory neurotransmitter of the central nervous system and has multiple functions in neurology; altered concentrations of GABA in human brain may be associated with various neurological disorders [49]. GABA-enriched foods have been positively developed recently because of their health functions. All kinds of GABA-enriched foods, including GABA tea, are under exploration and production, and it has been reported that intake of GABA-enriched foods can help to prevent from diabetes and control or inhibit cancer cells [50]. The GABA tea has been delivered as a commercial product for people with high blood pressure in Japan. 
GABA content is higher in fresh tea leaves from intercropping system, suggesting that this production system may be useful for the exploration and production of GABA-enriched tea.

\section{Organic acids may contribute to the increase of delicious flavors and the neurotransmitter}

Allantoate was reported to be vital for translocating $\mathrm{N}$ form and metabolic N currency in Acer species, and it is the major $\mathrm{N}$ form in spring sugar maple sap [51]. The partial intricate maple flavor originates from the Maillard reaction that takes place during the heating process in which allantoin and/or allantoate react with reducing sugars present in the sap [52]. In tea, allantoate may be involved in $\mathrm{N}$ transport and metabolism and may influence subsequent tea processing by the Maillard reaction, improving tea flavor in the intercropping samples.

The XA synthesis pathway is thought to be a partial detoxification process that lessens the content of 3hydroxykynurenine whose spontaneous oxidation causes free radical formation and apoptosis [53]. XA affects multiple molecular targets and signaling systems, and it influences brain function and neurotransmission in a wide range as one of the neuroactive kynurenine metabolites [54]. Moreover, XA can reduce oxidative DNA damage [55]. Nonetheless, there are very few reports on XA in higher plants in general or tea plants in particular, despite the fact that KA is found in tea [56]. This is probably the first report of XA in tea from an intercropping system.

Likewise, the upregulated metabolite 2-furoic acid has also been reported to improve the flavor and freshness in food industry [57]. The organic acid profile of tea changes when the fresh tea leaves are steamed during the manufacturing process: some are degraded, some are esterified, and some are increased to varying degrees [58]. Therefore, the organic acids present in fresh leaves provide the raw material for the final tea flavor and influence the formation of flavor substances during processing, in addition to simply contributing to their own sour taste. Organic acids in green tea can also inhibit bitterness and delay the perception of sweetness, and citric acid in particular can preserve the taste of tea [59]. The alterant organic acids here may be responsible for the improved green tea flavor from the intercropping system, although some of them were present in extremely low quantities and have rarely been reported in tea leaves.

\section{Up-regulated carbohydrates all contributed to the sweetness}

Mono- and oligosaccharides and their corresponding sugar alcohols are sweet, with a few exceptions [60]. Although the most important sweetener is saccharose (sucrose), other sugars and sugar alcohols are also important, differing in sweetness quality and taste intensity and providing different levels of sweetness [61]. The presence of free sugar in tea is also vital for the catechin synthesis, helps soluble solids, and promotes the biosynthesis of flavor components during processing [62]. Thus, the upregulation of carbohydrates is likely to improve the taste of brewed green tea.

Rhamnose, is widespread from bacteria to higher plants [63]; its sweetness is 33\% that of sucrose, and it can be used as a sweetener [61]. When both rhamnose and glucose are lost, and the taste is abolished [64], a result that highlights the important role of rhamnose in the taste of tea, despite its relatively low sweetness.

\section{Jasmine lactone contributes to the fruity, sweetness, floral aroma and oleic acid to health benefits}

Jasmine lactone is a lactone aroma component with a strong flavor with peach and apricot which occurs naturally in jasmine oil, gardenia, lily, tea, and other plants and contributes to the fruity, sweet floral aroma of tea [65]. Jasmine lactone is one of the important aroma constituents in tea [66], and the upregulation of jasmine lactone may help to explain the strong aroma of green tea from the intercropping samples. Oleic acid is a C18:1 monounsaturated fatty acid, and fresh tea leaves are rich in oleic acid, which can be broken down during tea processing [67]. Oleic acid has many beneficial effects on cellular health, heart health, weight management, brain function and type 2 diabetes [68]. Oleic acid may therefore contribute health benefits and characteristic flavor compounds during tea manufacturing, improving green tea quality in the intercropping system.

\section{Flavonoids may result in a decrease of bitterness and increased solubility in the green tea under intercropping} Naringin is a common plant flavonoid glycoside that contributes a bitter taste to tea [69]. Naringenin, the aglycone of naringin, is oxidized to apigenin by flavanone synthase [70]. The cyanogenic glucoside prunasin is the precursor to amygdalin and is also responsible for a very bitter taste in plants [71]. The flavonoid profile of intercropping samples was consistent with decreased bitterness and increased flavonoid solubility, which may have improved both the taste and the bioactivity of green tea.

Luteolin supplies specific anti-inflammatory and anticarcinogenic effects and controls the development of cancer cells [72]. The interaction of luteolin with cancer cells is similar to that of EGCG, which is a green tea polyphenol inhibiting tumor [73]. Moreover, apiin is also reported to display the functions of anti-inflammatory and anticancer [74]. In fact, many flavonoids function as free radical scavengers to protect humans from free radicals [75].

Pathways associated with flavonoids included numerous secondary metabolites with different metabolic functions in plants, including pigment synthesis, stress 
response and pathogen defense, among others [76], all of which are very important in tea plants. Significant changes in these pathways were also found in previous studies of tea leaves affected by shade treatment [77].

\section{Conclusion}

Green tea brewed from plants grown in a Chinese chestnut-tea intercropping system established in the 1980s on Baohong Mountain (80 T) ranked highest in sensory evaluation and had the lowest ratio of tea polyphenols to amino acids. LC-QTOFMS-based non-targeted metabolomics, UHPLC-MS/MS targeted metabolomics, and multivariate analysis was combined to investigate differences in the metabolite profiles of fresh tea leaves from the intercropping system compared with leaves grown in a pure tea cultivation system (T). We identified 100 differentially abundant metabolites, containing amino acids, organic acids, lipids, carbohydrates, as well as flavonoids. Many were related to flavor and bioactivity and appeared to provide rich raw materials for the improvement of green tea quality, including better taste and greater health benefits. Two pathways that are most closely related to flavor and bioactivity-flavone and flavonol biosynthesis and phenylalanine metabolism-showed the greatest differences in the positive and negative modes, respectively. Tea leaves from the two cropping systems showed numerous differences in pathways related to amino acid metabolism, indicating that the intercropping system greatly influenced amino acid metabolism, altering the accumulation and degradation of amino acid. These results enhance our understanding of the metabolic mechanisms that tea quality is improved in the Chinese chestnut-tea intercropping system, which is conducive to the scientific promotion of the intercropping system of Chinese chestnut and tea in the current situation of increasing shortage of land resources. As for the cause of altered metabolite levels, it may include various factors, including the shade provided by the trees, potential allelopathic effects between the trees and tea plants, below ground interactions between their roots, accumulation of organic material derived from the deciduous trees, etc., all of which require further investigation in the future.

\section{Supplementary Information}

The online version contains supplementary material available at https://doi. org/10.1186/s12870-021-02841-w.

Additional file 1: Figure S1. The total ion flow of positive (A) and negative (B) ion modes detected by LC-MS in the tea samples of $80 \mathrm{~T}$ (intercropping) vs. T (monoculture). Figure S2. Boxplots of absolute quantification of randomly selected amino acids in $80 \mathrm{~T}$ (intercropping) vs. T (monoculture). Each box contains the amino acid concentrations from samples of $80 \mathrm{~T}$ vs. T. Figure $\mathbf{S 3}$. Schematic diagram for tryptophan degrading into KA and XA. Table S1. Basic information of the tea samples. Table S2. Sensory evaluation of green tea samples

\section{Abbreviations}

ANOVA: Analysis of variance; BPI: Base peak intensity; CE: Collision energy; ISVF: Ion spray voltage floating; KEGG: Kyoto encyclopedia of genes and genomes; LC-MS: Liquid chromatography coupled with mass spectrometry; m/z: mass-to-charge ratio; MS: Mass spectrometry; MS2: Second mass spectrometer; OPLS-DA: Orthogonal projections to latent structuresdiscriminate analysis; PCA: Principal component analysis; QC: Quality control; QTOF: Quadrupole time-of-flight; ROS: Reactive oxygen species; RT: Retention time; UHPLC: Ultra high performance liquid chromatography; VIP: Variable importance in the projection

\section{Acknowledgements}

We would like to thank Mr. SU Tianshui, Chairman of Baohong tea farm in Yunnan province, China, for the sampling work of this study, the detailed introduction of the sampling site, and the provision of steaming green tea. We are grateful to BioTree Biotechnology Co., Ltd. Shanghai, China for the suggestions of metabonomic analysis. We also express our heartfelt thanks to Senior Tea-tasters Ms. SHEN Xiaojin and Ms. ZHOU Jinyan, who supported the sensory evaluation of tea samples.

\section{Authors' contributions}

TW designed the experiment, analyzed the data of metabolomics, and completed the manuscript; RZ participated in the sensory evaluation of tea, completed the detection of main functional components of tea and analyzed the data; ZL coordinated the experimental sampling site, organized sampling and tea sensory evaluation; DP participated in the sampling and analysis of metabolomics data; BZ put forward many constructive suggestions for the experimental design and revised the manuscript for many times. All authors have read and approved the manuscript.

\section{Funding}

This work was supported by grants from the fund of the Key Laboratory for Forest Resources Conservation and Utilization in the Southwest Mountains of China, Ministry of Education, Southwest Forestry University (No. KLESWFU201904) and the fund of China Scholarship Council (201908535030). We designed the study, collected and analyzed the data based on the former funding, and completed the manuscript writing and revision in Virginia Tech based on the latter funding.

\section{Availability of data and materials}

All data generated or analysed during this study are included in this published article and its supplementary information files. The datasets used and/or analysed during the current study are available from the corresponding author on reasonable request.

Ethics approval and consent to participate Not applicable.

Consent for publication Not applicable.

Competing interests

The authors declare that they have no competing interests.

\section{Author details}

'Key Laboratory for Forest Resources Conservation and Utilization in the Southwest Mountains of China, Ministry of Education, Southwest Landscape Architecture Engineering Research Center of State Forestry Administration, Southwest Forestry University, Kunming 650224, Yunnan, China. ${ }^{2}$ Ecology and Environment Department, Southwest Forestry University, Kunming 650224, Yunnan, China. ${ }^{3}$ Southwest Institute of Ecology Development, Southwest Forestry University, Kunming 650224, Yunnan, China. ${ }^{4}$ School of Plant and Environmental Sciences, Virginia Tech, Blacksburg, VA 24061, USA. 
Received: 9 October 2020 Accepted: 11 January 2021 Published online: 21 January 2021

\section{References}

1. Wang YS, Gao LP, Shan Y, Liu YJ, Tian YW, Xia T. Influence of shade on flavonoid biosynthesis in tea (Camellia sinensis (L.) O.Kuntze). Sci Hortic. 2012;141:7-16

2. Janendra WA, DeCostal M, Mohotti AJ. Ecophysiology of tea. Braz J Plant Physiol. 2007;19:299-332

3. Liebman M, Dyck E. Crop rotation and intercropping strategies for weed management. Ecol Appl. 1993;3:92-122.

4. Singh A, Weisser WW, Hanna R, Houmgny R, Zytynska SE. Reduce pests, enhance production, benefits of intercropping at high densities for okra farmers in Cameroon. Pest Manag Sci. 2017;73:2017-27.

5. Zhi XY, Han YC, Xing FF, Lei YP, Wang GP, Feng L, Yang BF, Wang ZB, Li XF, Xiong SW, Fan ZY, Li YB. How do cotton light interception and carbohydrate partitioning respond to cropping systems including monoculture, intercropping with wheat, and direct-seeding after wheat? PLoS One. 2019;14:e0217243.

6. Dai J, Qiu W, Wang N, Nakanishi H, Zuo Y. Comparative transcriptomic analysis of the roots of intercropped peanut and maize reveals novel insights into peanut iron nutrition. Plant Physiol Biochem. 2018;127:516-24.

7. Craswell ET, Sajjapongse A, Howlett DJB, Dowling AJ. Agroforestry in the management of sloping lands in Asia and the Pacific. Agrofor Syst. 1998;53: 121-37.

8. Chauhan SK, Gupta N, Walia R, Yadav S, Chauhan R, Mangat PS. Biomass and carbon sequestration potential of poplar-wheat inter-cropping system in irrigated agro-ecosystem in India. J Agr Sci Technol. 2011;1:575-86.

9. Xue J, Tang R. Practices and investigations of tree-tea intercropping systems in China. Int Tree Crops J. 1998;9(3):179-85.

10. Guo Z, Zhang Y, Deegen P, Uibrig H. Economic analyses of rubber and tea plantations and rubber-tea intercropping in Hainan, China. Agroforest Syst. 2006;66:117-27.

11. Li Q, Shi X, Zhao Q, Cui Y, Ouyang J, Xu F. Effect of cooking methods on nutritional quality and volatile compounds of Chinese chestnut (Castanea mollissima Blume). Food Chem. 2016;201:80-6.

12. Wang $\mathrm{H}, \mathrm{Wu} \mathrm{L}$, Zhou $\mathrm{M}$. Influence of chestnut-tea tree intercropping to growth of tea trees and tea quality in northern China. J Agrometeorol. 2005; 26(2):139-41.

13. Wan Y, Liu G, Zhou M. Study on major ecological factors of chestnut-tea intercrop garden. Nonwood Forest Res. 2009;27(3):57-60.

14. Ma YH, Fu S, Zhang X, Zhao K, Chen HYH. Intercropping improves soil nutrient availability, soil enzyme activity and tea quantity and quality. Appl Soil Ecol. 2017;119:171-8.

15. Yu LH, Liu GH, Chen SJ, Wang L, Shi L. Basis characteristics of tea root system under the condition of chestnut and tea intercropping. Nonwood Forest Res. 2006:24(3):6-10.

16. Das PR, Kim Y, Hong SJ, Eun JB. Profiling of volatile and non-phenolic metabolites - amino acids, organic acids, and sugars of green tea extracts obtained by different extraction techniques. Food Chem. 2019;296:69-77.

17. Saeed M, El-Hack MEA, Alagawany M, Naveed M, Arain MA, Arif M. Phytochemistry, modes of action and beneficial health applications of green tea (Camellia sinensis) in humans and animals. Int J Pharmacol. 2017;13(7): 698-708.

18. Yu ZM, Yang Z. Understanding different regulatory mechanisms of proteinaceous and non-proteinaceous amino acid formation in tea (Camellia sinensis) provides new insights into the safe and effective alteration of tea flavor and function. Crit Rev Food Sci Nutr. 2020;60:844-58.

19. Kellogg JJ, Graf TN, Paine MF, McCune JS, Kvalheim OM, Oberlies NH, Cech NB. Comparison of metabolomics approaches for evaluating the variability of complex botanical preparations: green tea (Camellia sinensis) as a case study. J Nat Prod. 2017;80(5):1457-66.

20. Zeng CZ, Lin HY, Liu ZX, Liu ZH. Analysis of young shoots of 'Anji Baicha'(Camellia sinensis) at three developmental stages using nontargeted LC-MS-based metabolomics. J Food Sci. 2019:84:1746-57.

21. Zhu B, Li L, Wei H, Zhou W, Zhou W, Li F, Lin P, Sheng J, Wang Q, Yan C, Cheng Y. A simultaneously quantitative profiling method for 40 endogenous amino acids and derivatives in cell lines using hydrophilic interaction liquid chromatography coupled with tandem mass spectrometry. Talanta. 2020;207:120256.
22. Li NN, Lu JL, Li QS, Zheng XQ, Wang XC, Wang L, Wang YC, Ding CQ, Liang YR, Yang YJ. Dissection of chemical composition and associated gene expression in the pigment-deficient tea cultivar 'Xiaoxueya' reveals an albino phenotype and metabolite formation. Front Plant Sci. 2019;10:1543.

23. Dursun A, Güler Z, Şekerli YE. Characterization of volatile compounds and organic acids in ultra-high-temperature milk packaged in tetra brik cartons. Int J Food Prop. 2017;20:1511-21.

24. Fang R, Redfern SP, Kirkup D. Variation of theanine, phenolic, and methylxanthine compounds in 21 cultivars of Camellia sinensis harvested in different seasons. Food Chem. 2017;220:517-26.

25. Liao J, Wu XY, Xing ZQ, Li QH, Duan Y, Fang WP, Zhu XJ. Y-Aminobutyric acid (GABA) accumulation in tea (Camellia sinensis L.) through the GABA shunt and polyamine degradation pathways under anoxia. J Agric Food Chem. 2017:65:3013-8.

26. Belitz HD, Chen W, Jugel H, Treleano R, Wieser H, Gasteiger J, Marsili M. Sweet and bitter compounds, structure and taste relationship. Food Taste Chem. 1979:4:93-131.

27. Ashihara $\mathrm{H}, \mathrm{Crozier} \mathrm{A}$. Biosynthesis and metabolism of caffeine and related purine alkaloids in plants. Adv Bot Res. 1999:30:117-205.

28. Mazzafera P. Catabolism of caffeine in plants and microorganisms. Front Biosci. 2004:9:1348-59.

29. Mohanpuria P, Kumar V, Joshi R, Gulati A, Ahuja PS, Yadav SK. Caffeine biosynthesis and degradation in tea [Camellia sinensis (L.) O. Kuntze] is under developmental and seasonal regulation. Mol Biotechnol. 2009;43:104-11.

30. Zsizsik BK, Hardeland R. Formation of kynurenic and xanthurenic acids from kynurenine and 3-hydroxykynurenine in the dinoflagellate Lingulodinium polyedrum, role of a novel, oxidative pathway. Com. Biochem Physiol Part C Toxicol Pharmacol. 2002:133:383-92.

31. Muchuweti M, Zenda G, Ndhlala AR, Kasiyamhuru A. Sugars, organic acid and phenolic compounds of Ziziphus mauritiana fruit. Eur Food Res Technol. 2005;221:570-4

32. Ali MB, Mhiri S, Mezghani M, Bejara S. Purification and sequence analysis of the atypical maltohexaose-forming a-amylase of the B. stearothermophilus US100. Enzym Microb Technol. 2001:28(6):537-42.

33. Robyt JF. Sweetness. In: Essentials of Carbohydrate Chemistry; 1998. p. 142-56.

34. Derollez $P$, Guinet $Y$, Affouard F, Danède F, Carpentier L, Hédoux A. Structure determination of I-arabinitol by powder X-ray diffraction. Acta Crystallogr B. 2012;68:407-11.

35. Van Es AJH. Dietary energy density on using sugar alchohols as replacements for sugars. Proc Nutr Soc. 1991;50(2):383-90.

36. Gales MA, Nguyen TM. Sorbitol compared with xylitol in prevention of dental caries. Ann Pharmacother. 2000;34:98-100.

37. Saotome Y, Imai M. Supercritical carbon dioxide extraction of apigenin from parsley leaves pre-treated to maximize yield. Food Sci Technol Res. 2018; 24(1):63-73.

38. Dong F, Yang Z, Baldermann S, Kajitani Y, Ota S, Kasug H, Imazeki Y, Ohnishi T, Watanabe N. Characterization of I-phenylalanine metabolism to acetophenone and 1-phenylethanol in the flowers of Camellia sinensis using stable isotope labeling. J Plant Physiol. 2012;169(3):217-25.

39. Ekborg-Ott KH, Taylor A, Armstrong DW. Varietal differences in the total and enantiomeric composition of theanine in tea. J Agric Food Chem. 1997;45: 353-63

40. Narukawa M, Morita K, Hayashi Y. L-Theanine elicits an umami taste with inosine 5'-monophosphate. Biosci Biotechnol Biochem. 2008;72(11):3015-7.

41. Lee LS, Kim SH, Kim YB, Kim YC. Quantitative analysis of major constituents in green tea with different plucking periods and their antioxidant activity. Molecules. 2014;19:9173-86.

42. Lean MEJ, Hankey CR. Aspartame and its effects on health. BMJ. 2004;329: 755.

43. Ogawa $T$, Nakamura T, Tsuji E, Miyanaga $Y$, Nakagawa $H$, Hirabayashi $H$, Uchida T. The combination effect of $\mathrm{L}$-arginine and $\mathrm{NaCl}$ on bitterness suppression of amino acid solutions. Chem Pharm Bull. 2004;52:172-7.

44. Miyashita T, Etoh $\mathrm{H}$. Improvement of the bitterness and astringency of green tea by sub-critical water extraction. Food Sci Technol Res. 2013;19(3): 471-8.

45. Moya-Garcia AA, Medina MA, Sánchez-Jiménez F. Mammalian histidine decarboxylase: from structure to function. Bioessays. 2005;27(1):57-63.

46. Wu GY. Amino acids, metabolism, functions, and nutrition. Amino Acids. 2009;37:1-17

47. Shao H, Chu L, Shao M, Jaleel CA, Mi H. Higher plant antioxidants and redox signaling under environmental stresses. C R Biol. 2008;331(6):433-41. 
48. Devasagayam TPA, Tilak JC, Boloor KK, Sane KS, Ghaskadbi SS, Lele RD. Free radicals and antioxidants in human health: current status and future prospects. J Assoc Physicians India. 2004;52:794-804.

49. Ben-Ari Y, Khalilov I, Kahle KT, Cherubini E. The GABA excitatory/inhibitory shift in brain maturation and neurological disorders. Neuroscientist. 2012;18: 467-86.

50. Dhakal R, Bajpai VK, Baek KH. Production of GABA ( $\gamma$-aminobutyric acid) by microorganisms, a review. Braz J Microbiol. 2012;43(4):1230-41.

51. Barnes RL. Formation of allantoin and allantoic acid from adenine in leaves of Acer saccharinum L. Nature. 1959;184:1944.

52. Perry JJ, Fiore MC. A comprehensive review of maple sap microbiota and its effect on maple syrup quality. Food Rev Int. 2020. https://doi.org/10.1080/ 87559129.2020.1788579.

53. Wei $H$, Leeds $P$, Chen RW, Wei W, Leng Y, Bredesen DE, Chuang DM. Neuronal apoptosis induced by pharmacological concentrations of 3hydroxykynurenine, characterization and protection by dantrolene and $\mathrm{BCl}-2$ overexpression. J Neurochem. 2000;75:81-90.

54. Fazio F, Lionetto L, Curto M, Lacovelli L, Copeland CS, Neale SA, Bruno V, Battaglia G, Salt TE, Nicoletti F. Cinnabarinic acid and xanthurenic acid: two kynurenine metabolites that interact with metabotropic glutamate receptors. Neuropharmacology. 2017:112:365-72.

55. Lopez-Burrillo S, Tan DX, Mayo JC, Sains RM, Manchester LC, Reiter RJ. Melatonin, xanthurenic acid, resveratrol, EGCG, vitamin C and a-lipoic acid differentially reduce oxidative DNA damage induced by Fenton reagents: a study of their individual and synergistic actions. J Pineal Res. 2003;34:269-77.

56. Yilmaz C, Özdemir F, Gökmen V. Investigation of free amino acids, bioactive and neuroactive compounds in different types of tea and effect of black tea processing. LWT. 2020;117:108655.

57. Hucker $B$, Varelis $P$. Thermal decarboxylation of 2 -furoic acid and its implication for the formation of furan in foods. Food Chem. 2011;126:1512-3.

58. Sanderson GW, Selvendran RR. The organic acids in tea plants. A study of the non-volatile organic acids separated on silica gel. J Sci Food Agric. 1965; 16(5):251-8

59. Chaturvedula VSP, Prakash I. The aroma, taste, color and bioactive constituents of tea. J Med Plants Res. 2011;5(11):2110-24.

60. Rogers WJ, Michaux S, Bastin M, Bucheli P. Changes to the content of sugars, sugar alcohols, myo-inositol, carboxylic acids and inorganic anions in developing grains from different varieties of Robusta (Coffea canephora) and Arabica (C. arabica) coffees. Plant Sci. 1999;149(2):115-23.

61. Belitz HD, Grosch W, Schieberle P. Sugars, sugar alcohols and honey. In: Food Chemistry; 2004. p. 862-91.

62. Xu YQ, Chen SQ, Yuan HB, Tang P, Yin JF. Analysis of cream formation in green tea concentrates with different solid concentrations. Food Sci Technol. 2012:49(3):362-7.

63. Giraud MF, Naismith JH. The rhamnose pathway. Curr Opin Struct Biol. 2000; 10(6):687-96.

64. Horowitz RM, Gentili B. Taste and structure in phenolic glycosides. J Agric Food Chem. 1969;17:696-700.

65. Zeng LT, Zhou Y, Fu XM, Liao YY, Yuan YF, Jia YX, Dong F, Yang ZY. Biosynthesis of jasmine lactone in tea (Camellia sinensis) leaves and its formation in response to multiple stresses. J Agric Food Chem. 2018;66: 3899-909.

66. Wang X, Wang D, Li J, Ye C, Kubota K. Aroma characteristics of cocoa tea (Camellia ptilophylla Chang). Biosci Biotechnol Biochem. 2010;74(5):946-53.

67. Chung TY, Kuo PC, Liao ZH, Shih YE, Yang ML, Cheng ML, Wu CC, Tzen JTC. Analysis of lipophilic compounds of tea coated on the surface of clay teapots. J Food Drug Anal. 2015;23(1):71-81.

68. Sales-Campos H, Reis de Souza P, Crema Peghini B, Santana da Silva J, Ribeiro Cardoso C. An overview of the modulatory effects of oleic acid in health and disease. Mini-Rev Med Chem. 2013;13(2):201-10.

69. Pękal A, Biesaga M, Pyrzynska K. Trace metals and flavonoids in different types of tea. Food Sci Biotechnol. 2013;22:925-30.

70. Oyama K, Kondo T. Total synthesis of apigenin 7,4'-di-O- $\beta$-glucopyranoside, a component of blue flower pigment of Salvia patens, and seven chiral analogues. Tetrahedron. 2004;60(9):2025-34.

71. Sánchez-Pérez R, Howad W, Garcia-Mas J, Arús P, Martínez-Gómez P, Dicenta F. Molecular markers for kernel bitterness in almond. Tree Genet Genomes. 2010;6:237-45.

72. Seelinger G, Merfort I, Schempp CM. Anti-oxidant, anti-inflammatory and anti-allergic activities of luteolin, a flavone from the Dyer's weld Reseda luteola L. Planta Med. 2008;74:1667-77.
73. Chen L, Zhuang HY. Cancer preventive mechanisms of the green tea polyphenol (-)-epigallocatechin-3-gallate. Molecules. 2007;12:946-57.

74. Siddique YH, Beg T, Afzal M. Antigenotoxic effect of apigenin against anticancerous drugs. Toxicol Vitro. 2008;22(3):625-31.

75. Moridani MY, Pourahmad J, Bui H, Siraki A, O'Brien PJ. Dietary flavonoid iron complexes as cytoprotective superoxide radical scavengers. Free Radical Biol Med. 2003;34(2):243-53.

76. Ferreyra MLF, Rius SP, Casati P. Flavonoids, biosynthesis, biological functions, and biotechnological applications. Front Plant Sci. 2012;3:222.

77. Liu LL, Li YY, She GB, Zhang XC, Jordan B, Chen Q, Zhao J, Wan XC. Metabolite profiling and transcriptomic analyses reveal an essential role of UVR8-mediated signal transduction pathway in regulating flavonoid biosynthesis in tea plants (Camellia sinensis) in response to shading. BMC Plant Biol. 2018;18:233.

\section{Publisher's Note}

Springer Nature remains neutral with regard to jurisdictional claims in published maps and institutional affiliations.
Ready to submit your research? Choose BMC and benefit from:

- fast, convenient online submission

- thorough peer review by experienced researchers in your field

- rapid publication on acceptance

- support for research data, including large and complex data types

- gold Open Access which fosters wider collaboration and increased citations

- maximum visibility for your research: over $100 \mathrm{M}$ website views per year

At BMC, research is always in progress.

Learn more biomedcentral.com/submissions 